\title{
Siglas e abreviaturas
}

ADIPC - Aspectos de Direitos de Propriedade Intelectual Relacionados com o Comércio / o mesmo que TRIPS

CAAAM - Comité Andino de Autoridades Ambientales

CAN - Comunidad Andina

CB - Convenção sobre Biodiversidade

Cl - Conservation International do Brasil

CIDOB - Confederación de Pueblos Indígenas de Bolivia

CPTI - Centro de Planificação Indígena

CITES - Convenção sobre o Comércio Internacional das Espécies da Flora e da

Fauna Selvagens em Perigo de Extinção

CNUMAD - Conferência das Nações Unidas para o Meio Ambiente e

Desenvolvimento

COP - Conferência das Partes

CPF - Consentimento Prévio Fundamentado

CTS - Conhecimentos Tradicionais

DGB - Dirección General de Biodiversidad

DPI - Direitos de Propriedade Intelectual

F.A.N - Fundación Amigos de La Naturaleza Noel Kempff

FAO - Organização das Nações Unidas para a Alimentação e Agricultura

FOBOMADE - Foro Boliviano sobre Medio Ambiente y Desarrollo

GATT - General Agreement on Tarifs and Trade / Acordo Geral de Tarifas e Comércio

INRA - Ley del Servicio Nacional de la Reforma Agrária de 1996.

IUCN - International Union for the Conservation of Nature

OIT - Organização Internacional do Trabalho

OMC - Organização Mundial do Comércio

OMPI - Organização Mundial da Propriedade Intelectual

ONG - Organização Não Governamental

ONU - Organização das Nações Unidas 
PNUMA - Programa das Nações Unidas para o Meio Ambiente

Ramsar - Convenção Relativa a Zonas Úmidas de Importância Internacional, Particularmente como Habitat de Aves Aquáticas

TCA - Tratado de Cooperação Amazônica

TCO - Terras Comunitárias de Origem

TRIPs - Trade Related Aspects of Intellectual Property Rights / acordo sobre a proteção da propriedade intelectual - o mesmo que ADIPC

USDA - Departamento de Agricultura dos Estados Unidos

WWF - World Wildlife Fund 